\title{
Thermoluminescence Properties of Fly Ash with Divalent Anion Composite for High Dose TL Dosimetric Application
}

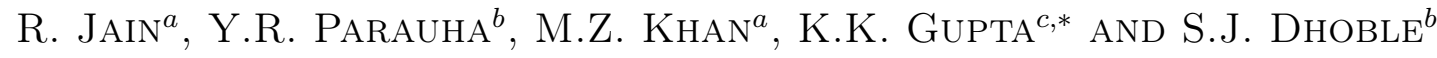 \\ ${ }^{a}$ Department of Physics, Dr. C.V. Raman University, Bilaspur, India \\ ${ }^{b}$ Department of Physics, R.T.M.Nagpur University, Nagpur-440033, India \\ ${ }^{c}$ Department of Chemical Engineering, National Taiwan University, Taipei, Taiwan, ROC
}

Received: 01.04.2020 \& Accepted: 01.07.2020

Doi: 10.12693/APhysPolA.138.497 *e-mail: k2gnsv33@gmail.com

\begin{abstract}
In this study, we have synthesized fly ash composite materials with a divalent anion. Thermoluminescence (TL) characteristics of fly ash composite materials were recorded after irradiation by ${ }^{60} \mathrm{Co}$ gamma exposure. TL glow curve at around $203{ }^{\circ} \mathrm{C}$ was observed in case of divalent anion doped phosphor. Co-doping of divalent anion changes the TL peak positions by 2 to $10^{\circ} \mathrm{C}$. TL dose response curve of fly ash composite was also recorded. The dosimetric TL peak was observed at high temperature and hence less fading of TL signal was recorded for twelve days of a storage period. The TL response of the fly ash composite may be considered to be satisfactory for applications in high dose dosimeters. TL trapping parameters, such as order of kinetics $(b)$, activation energy $(E)$, and frequency factor $(s)$ associated with the most intensive glow peak of fly ash composite materials, were determined by using
\end{abstract} Chen's peak shape method and are reported in this paper.

topics: thermoluminescence, dosimetry, high dose: fly ash

\section{Introduction}

In the age of digitization, energy demand daily increases but our energy sources are limited. In this modern era, energy planners are aiming to increase electricity supply in India by using oil, gas, nuclear, and renewable energy sources. For the past few years, India has been one of the leading world producers of renewable energy [1]. Renewable energy is the energy that is directly collected from renewable sources such as sunlight, wind, rain, tides, waves, etc. It often provides energy for electricity generation, air and water heating/cooling,transportation, and rural (off-grid)energy services [2, 3].

At present coal-based thermal power plants are the major source of electricity generation and they will continue to dominate in the next few decades. One of the major disadvantages of coal-based thermal power plants is a problem with fly ash disposal. It was earlier considered as a total waste and an environmental hazard so its use was limited but without much comprehension. Fortunately, because of its useful properties, it has now begun to be considered a useful raw material for various applications $[4,5]$. Fly ash is a byproduct of burning pulverized coal in electric power generating plants. During combustion, mineral impurities in the coal (clay, feldspar, quartz, and shale) fuse in suspension and float out of the combustion chamber with the exhaust gases. As the fused material rises, it cools and solidifies into spherical glassy particles called fly ash [6]. There are numerous advantages of fly ash utilization such as energy-saving, protection of environment and agriculture. In construction it can also partly replace cement [7].

Thermoluminescence is one of the processes in thermally stimulated phenomena of light from an insulator/semi-conductor following a previous absorption of energy from ionizing radiation including $\gamma$-rays, X-rays, $\beta$-particles, $\alpha$-particles, protons, neutrons and energetic ions [8]. In general, TL is the phenomenon of light emission when radiation is incident on a material; some of its energy may be absorbed and re-emitted as light with longer wavelength. Low dose and high dose phosphor is characterized by thermoluminescence (TL) emission which is utilized in medical and environmental radiation dosimetry. In general, TLD materials exhibit high concentration of traps, negligible fading and simple trap distribution in highly efficient TL phosphors. The dosimetric peak should have a peak temperature in the range of $180-250^{\circ} \mathrm{C}$ and good resistance against disturbing environmental factors such as humidity, moisture, and organic and inorganic gases. A TL phosphor should have a low phonon energy dependence of response and a linear TL response over a wide range of doses. The TL phosphor should be non-toxic for the medical, 
food, and environmental dosimetry. A TLD phosphor should exhibit good thermal and radiation stability and good linear energy transfer (LET) sensitivity. TLD phosphors may also be applied in nuclear power plants and aircraft [9].

A concentrated research is desirable to find out more areas for fly ash utilization. The presence of several inorganic compounds in fly ash enhances the probability of finding its TL properties. Hence, the fly ash and fly ash composites as a TL dosimeter have been examined in the present study. We have used fly ash samples collected from a location in India. The outcomes from the study indicated that the TL glow curve of the composite fly ash comprises a broad glow curve and has wide linear TL response. The linear TL response is better than the previously reported study of pristine fly ash [10]. Chen's peak shape method was used for the calculation of trapping parameters such as activation energy; frequency factor and order of kinetics [11]. The lifetime of the dominant peak was also estimated to find the stability of a TL signal at room temperature.

\section{Experimental}

The grade $\mathrm{F}$ fly ash used in this experiment was collected from the Sipat Thermal Power Station. Sipat is a town $25 \mathrm{~km}$ away from Bilaspur (C.G.), India. The source of coal for the power plant is Dipika Mines of South Eastern Coalfields Limited. Six samples based on fly ash were prepared. The first sample contained pristine fly ash and was named FLA while other samples containing fly ash with lime, $\mathrm{BaCO}_{3}$ or $\mathrm{SrCO}_{3}$ or $\mathrm{CaCO}_{3}$ or $\mathrm{BaCO}_{3}, \mathrm{SrCO}_{3}$, and $\mathrm{CaCO}_{3}$ were named FLAL, FLALB, FLALS, FLALC, and FLALBSC, respectively. All extra impurities were added in equal proportion to fly ash, grinded using mortal and pastel for $3 \mathrm{~h}$ and finally the sample was transferred to a muffle furnace for heating at $400^{\circ} \mathrm{C}$.
The X-Ray Diffraction (XRD) pattern of FLALC sample was characterized by a Rigaku mini flex 600 X-ray diffractometer using $\mathrm{CuK}_{\alpha}$ line having wavelength $\lambda=1.5406 \AA$ with a slow scanning rate of $0.02^{\circ}$ in $2 \theta$ range of $10^{\circ}$ to $80^{\circ}$. The SEM image of FLALC sample was obtained from Carl ZEISS EVO 18 at $5000 \mathrm{~V}$ accelerating voltage and $2.5 \mathrm{~mA}$ probe current. Fourier Transform Spectra of the FLALC sample were analyzed using a BRUCKER ALPHA FTIR Spectrometer. The thermoluminescence properties of all fly ash composites were studied by irradiating the sample powder by using ${ }^{60} \mathrm{Co}$ gamma source. TL glow curves of $\gamma$-ray irradiated samples were obtained using a Nucleonix 1009I TL reader in the temperature range of $50^{\circ} \mathrm{C}$ to $300^{\circ} \mathrm{C}$ with a $5^{\circ} \mathrm{C}$ heating rate. For the TL study a $5 \mathrm{mg}$ sample was used in each measurement.

\section{Results and discussion}

\subsection{Composition and classification of fly ash}

The composition of fly ash depends on the type of coal burned such as anthracite, bituminous coal, or lignite. Fly ash is generally a heterogeneous material having particles in the spherical form and size varies from $0.5 \mu \mathrm{m}$ to $300 \mu \mathrm{m}$. Generally, fly ash is divided into two classes: Class $\mathrm{F}$ and Class $\mathrm{C}$ fly ash as defined by ASTM C618. The chief difference between these classes is the amount of calcium, silica, alumina, and iron content in the ash. Class $\mathrm{F}$ fly ash is very hard and pozzolanic in nature. It contains less than $7 \%$ of lime. Class $\mathrm{C}$ fly ash hardens and gets stronger over time. Class C fly ash is a product of burned younger lignite or sub-bituminous coal. Class $\mathrm{C}$ fly ash generally contains more than $20 \%$ of lime. The main chemical components present in fly ashes are $\mathrm{SiO}_{2}, \mathrm{Al}_{2} \mathrm{O}_{3}$, $\mathrm{Fe}_{2} \mathrm{O}_{3}, \mathrm{~K}_{2} \mathrm{O}, \mathrm{TiO}_{2}$, and $\mathrm{CaO}$. Fly ash samples have a very wide or broad field in geology. The color of fly ash is also one of its most important properties.

TABLE I

Test results obtained for chemical composition of FLA, FLAL, FLALB, FLALS, FLALC and FLALBSC samples (in $\%$ of $1 \mathrm{gm}$ ).

\begin{tabular}{l|c|c|c|c|c|c}
\hline \hline Parameter & FLA & FLAL & FLALB & FLALS & FLALC & FLALBSC \\
\hline $\mathrm{Na}_{2} \mathrm{O}$ & 0.1496 & 0.1132 & 0.4802 & 1.2617 & 0.0992 & 0.7475 \\
$\mathrm{MgO}$ & 0.4630 & 1.9667 & 1.4437 & 2.3468 & 5.6853 & 3.5383 \\
$\mathrm{Al}_{2} \mathrm{O}_{3}$ & 28.2566 & 13.1859 & 7.2213 & 8.2318 & 7.6101 & 3.4592 \\
$\mathrm{SiO}_{2}$ & 61.1350 & 29.6331 & 15.4180 & 17.3824 & 17.108 & 7.6107 \\
$\mathrm{~K}_{2} \mathrm{O}$ & 1.3061 & 0.8018 & 0.4043 & 0.5172 & 0.4931 & 0.2393 \\
$\mathrm{CaO}$ & 1.1716 & 49.3219 & 34.364 & 53.884 & 64.7002 & 37.7272 \\
$\mathrm{TiO}_{2}$ & 2.0656 & 1.2913 & 0.8220 & 1.1965 & 0.9888 & 0.4894 \\
$\mathrm{Fe}_{2} \mathrm{O}_{3}$ & 4.6604 & 3.1161 & 2.1744 & 3.3901 & 2.6731 & 1.3762 \\
$\mathrm{MnO}$ & 0.0361 & 0.0272 & 0.0230 & 0.03464 & 0.0351 & 0.016 \\
$\mathrm{BaO}$ & - & - & 0.6035 & - & - & 19.1278 \\
$\mathrm{Cl}$ & - & - & - & 1.4403 & - & - \\
$\mathrm{SrO}$ & - & - & - & 9.4094 & - & 24.5298
\end{tabular}


A lighter color indicates a high content of calcium oxide while a darker color denotes a higher organic content. The principal constituents of fly ash and its composites were measured using Full analysis Vac $34 \mathrm{~mm}$ method. The constituentes may vary depending on the variation of coal from source and design of coal fired boilers. Fly ash always contains significant amounts of $\mathrm{SiO}_{2}, \mathrm{Al}_{2} \mathrm{O}_{3}$, and $\mathrm{CaO}$. The constituents of all the samples are as follows.

Table I represents the chemical composition of pristine fly ash and anion composite fly ash samples. The content of calcium oxide for FLA sample was $1.17 \%$ while for FLAL and FLALC samples the amount increased to $49.32 \%$ and $64.7 \%$, respectively. The extra content of $\mathrm{BaO}$ and $\mathrm{SrO}$ was detected at the level of $0.6 \%$ and $9.4 \%$ for FLALB and FLALS samples due to the addition of $\mathrm{BaCO}_{3}$ and $\mathrm{SrCO}_{3}$ anion impurities to pristine fly ash sample. The effect of intentionally added impurities has a direct effect on the TL properties of the fly ash sample which is discussed in the later section.

\subsection{X-Ray Diffraction (XRD) Analysis}

The crystalline phase of the sample was analyzed using X-ray diffraction (XRD) pattern at room temperature in $2 \theta$ range from $10^{\circ}$ to $80^{\circ}$. Figure 1 represents the XRD pattern of the FLALC sample. The XRD pattern of as synthesized fly ash composite material (FLALC) indicates complex multiphases which are the extensive overlap of the strong peaks of many phases and may leave no obvious unique peaks to be used for quantization. Three major peaks are observed in the XRD pattern indicating the presence of Quartz $\left(\mathrm{SiO}_{2}\right)$, Mullite $\left(3 \mathrm{Al}_{2} \mathrm{O}_{3}-\mathrm{SiO}_{2}\right)$, and $\mathrm{CaO}$ phases. In the XRD pattern, other phases are observed due to the presence of several inorganic contents of fly ash which has already been reported in earlier works. However, the presence of the $\mathrm{CaO}$ phase is due to the addition of lime and $\mathrm{CaCo}_{3}$ to the fly ash.

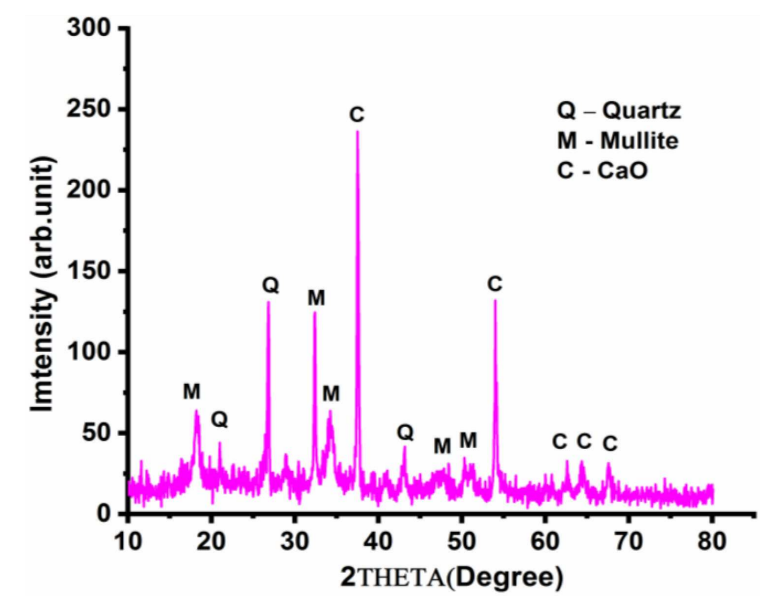

Fig. 1. XRD pattern of as synthesized FLALC sample.

\subsection{Scanning Electron Microscope (SEM)}

The structural and morphological properties were analyzed using a Scanning Electron Microscope (SEM) characterization and they are shown in Fig. 2. FLALC sample was chosen for the SEM analysis. Most of the particles have irregular shapes and sizes while other particles have a spherical shape having an average diameter of $10 \mu \mathrm{m}$. Since the particle size has a direct effect on TL intensity thus it should be measured with high precision. The micro particle grains have higher TL intensity than nano particles. In our case, the particle size ranges between 10 and $20 \mu \mathrm{m}$.

\subsection{Fourier-transform infrared spectroscopy} (FTIR) analysis

Figure 3 shows the FT-IR spectrum of the fly ash sample containing extra lime and $\mathrm{CaCO}_{3}$ which was named FLALC. The recorded FT-IR spectrum represents various vibration modes. The peak present at $3641 \mathrm{~cm}^{-1}$ is due to the $\mathrm{C}-\mathrm{OH}$ vibration mode while other peaks present in between $1600-1650 \mathrm{~cm}^{-1}$ and $1750-1850 \mathrm{~cm}^{-1}$ represent $\mathrm{C}=\mathrm{O}$ vibration modes. The FTIR peak observed in between $1150-1050 \mathrm{~cm}^{-1}$ represents $\mathrm{C}-\mathrm{O}$ vibrations. The absorption peak at 480 and $420 \mathrm{~cm}^{-1}$ is due to the bending and rocking modes of $\mathrm{Si}-\mathrm{O}$ bonds and due to the vibration of $\mathrm{Ca}-\mathrm{O}$ complexes present in the FLALC sample, respectively. The case of $1082 \mathrm{~cm}^{-1}$ peak represents an asymmetric stretching of Si-O-Si and $\mathrm{Al}-\mathrm{O}-\mathrm{Si}$ bonds.
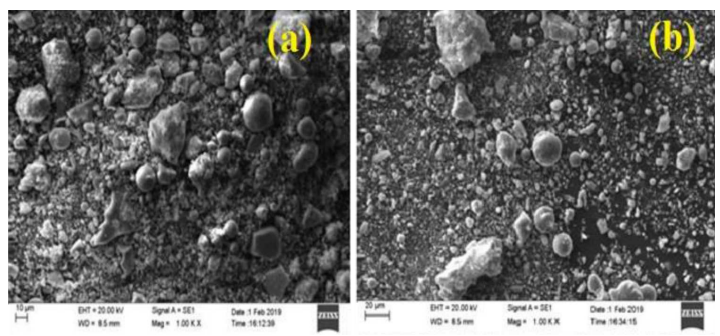

Fig. 2. SEM micrographs of as synthesized FLALC sample.

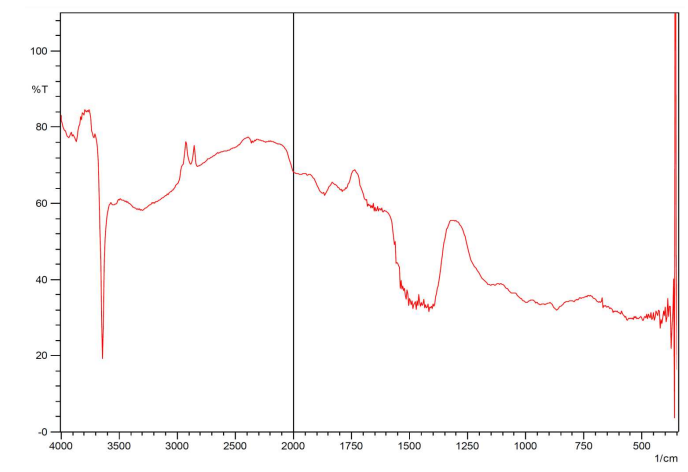

Fig. 3. FTIR spectra of as synthesized FLALC sample. 


\subsection{TL glow curves analysis}

TL is a popular technique to identify the defects and dosimetric property of a semiconductor or insulator type material after irradiation by ionizing radiations [12]. During irradiation the entire energy of $\gamma$-ray is absorbed by the material through three different mechanisms including photoelectric effect, Compton effect, and pair production. Ionizing radiation breaks bonds between atoms in molecules to create free radicals. These free radicals are trapped at defect centers and stored in terms of the amount of radiation absorbed. Figure 4 shows the TL glow curves of six different $\gamma$-ray irradiated samples at $14.4 \mathrm{kGy}$ dose by using ${ }^{60} \mathrm{Co}$ source. It was observed that the FLALC sample has a well-defined and single TL glow peak towards a higher temperature region while other samples have multiple peaks ranging from lower to higher temperature regions. It means that FLALC sample has simple trap distribution while other samples have complex trap distribution and do not display dosimetric properties. The maximum TL intensity was observed around $203^{\circ}$ for FLALC sample. Unirradiated samples of fly ash do not show any TL response, indicating the absence of any environmental radiation source surrounding the areas from where the fly ash was collected. Since the TL glow curve of FLALC sample has all the dosimetric characteristics, we have used this sample for our further studies such as dose linearity, calculation of trapping parameters, fading, and total lifetime.

\subsection{TL dose response}

The TL technique is used for determining a radiation dose. Therefore, it is necessary to record TL response at different radiation doses. The TL intensity should be linear with increasing the duration of radiation exposure in such a way that the value of doses absorbed by the material [13] could be easily predicted. Figure 5 represents the TL glow

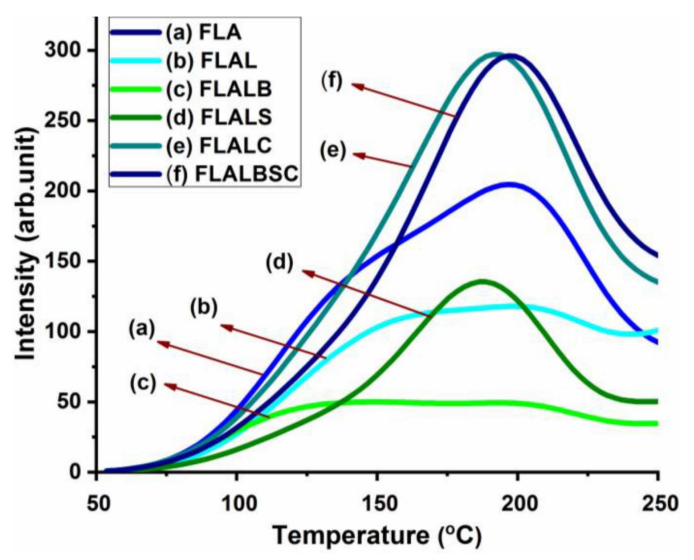

Fig. 4. TL glow curves of fly ash and fly ash composites exposed to $\gamma$-rays of $14.4 \mathrm{kGy}$ dose from ${ }^{60}$ Co source.

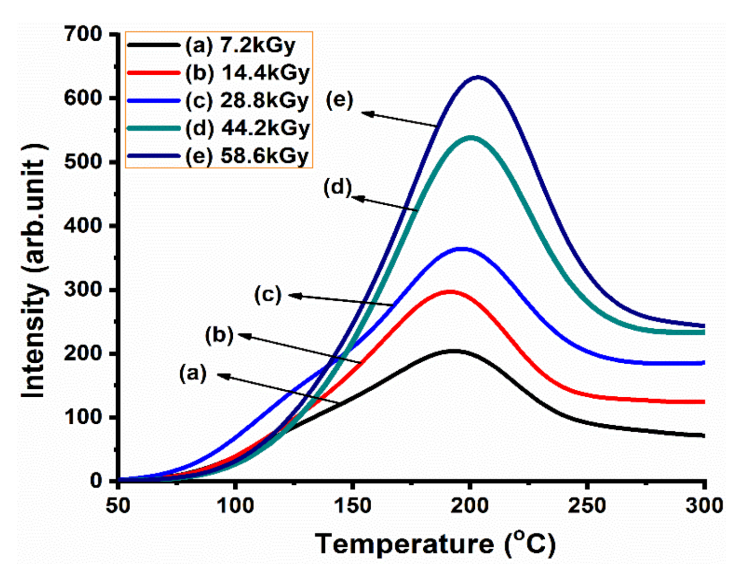

Fig. 5. TL glow curves of FLALC sample exposed to $\gamma$-rays for different doses.

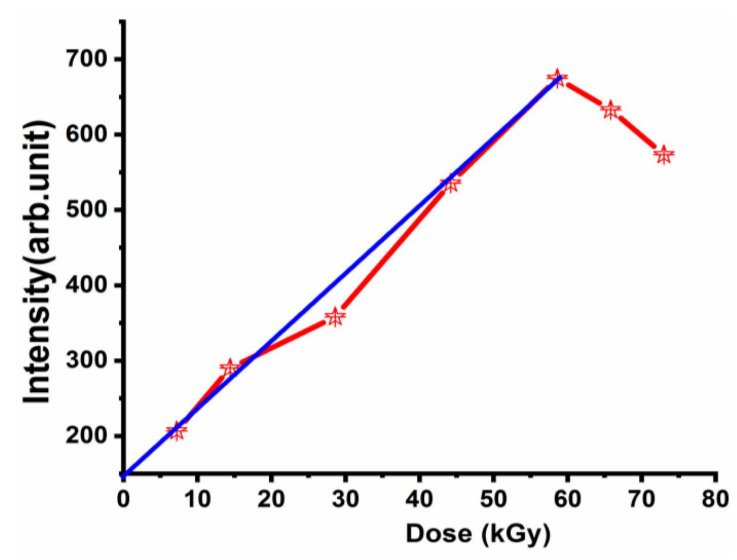

Fig. 6. TL dose response curve of FLALC sample to different $\gamma$-doses.

curves of FLALC sample exposed to $\gamma$-rays at different doses ranging from $7.2 \mathrm{kGy}$ to $58.6 \mathrm{kGy}$. FLALC sample irradiated up to $28.8 \mathrm{kGy}$ showed a small hump towards a lower temperature side with the dominant peak while at higher doses only the dominant peak was present. Its intensity increased with increasing the dose up to $58.6 \mathrm{kGy}$. The change in the relative intensity of the glow peaks can be attributed to the change in the population of the luminescence and trapping centers. The number of luminescence and trapping centers has increased linearly inside FLALC sample with increasing the dose values and has given rise to enhanced TL intensity. According to Horowitz et al., the linear response of the TL glow curve can be explained in the framework of defect interaction model (DIM) [14]. The linear response arises from the recombination of localized entity which is an electron/hole pair and acts as a trapping/luminescence center. The competitive process (unoccupied electron/hole trap) is suppressed during the linear response of the TL glow curve. Variation in the peak temperature position was observed with a change in radiation dose value which indicates the absence of the first-order kinetic behavior of TL peak 
TABLE II

Comparison data of FLALC sample and previously reported samples.

\begin{tabular}{l|c|c|c}
\hline \hline \multicolumn{1}{c|}{ Sample } & $\begin{array}{c}\text { TL peak } \\
\text { position }\left[{ }^{\circ} \mathrm{C}\right]\end{array}$ & $\begin{array}{c}\text { Dose } \\
\text { linearity [kGy] }\end{array}$ & Ref. \\
\hline $\mathrm{KCaPO}_{4}: \mathrm{Dy}$ & 155 & 2 & {$[16]$} \\
$\mathrm{CaF}_{2}: \mathrm{Dy}$ & 183 & 12 & {$[17]$} \\
$\mathrm{BaB}_{4} \mathrm{O}_{7}: \mathrm{Ce}$ & 175,311 & 3 & {$[18]$} \\
fly ash & $141,205,285,347$ & 40 & {$[10]$} \\
natural calcite & 283 & 1 & {$[19]$} \\
FLALC & 203 & 58.6 & here
\end{tabular}

under study. TL response curve of FLALC sample at different doses is shown in Fig. 6. The dose ranged from $7.2 \mathrm{kGy}$ to $73 \mathrm{kGy}$. The TL response curve clearly indicates the linear TL response with the dose limit of $58.6 \mathrm{kGy}$. In our previously reported study, the linear response of fly ash was only up to the $40 \mathrm{kGy}$ while the addition of lime and $\mathrm{CaCO}_{3}$ in the present work increased the radiation absorption ability of fly ash and resulted in a high dose response [15].

In the present study we have compared our data with the previously reported work. Table II compares data of the as synthesized FLALC with data from the previously reported work. It can be clearly observed that the dose linearity of $58.6 \mathrm{kGy}$ is highest among the other reported data. However, the single peak position near $203^{\circ} \mathrm{C}$ indicates a stable TL glow curve which is also comparable to other reported studies. It can be stated that in the near future fly ash could become one of the choices as a dosimetric material.

\subsection{Storage time effect on TL glow curve}

Fading is one of the most important factors to study out of all dosimetric properties of any TLD material. We can calculate the total loss of TL signal over particular storage of irradiated TLD material using a fading analysis. We had stored our sample without any protection from sunlight, humidity, and other environmental conditions. The loss of TL signal was measured in the interval of two days and shown in Fig. 7. FLALC sample was irradiated by $28.8 \mathrm{kGy}$ dose and stored for twelve days for a fading study. The total loss of TL signal was only $18 \%$ over the entire storage period. It could be concluded from the fading study that the total fading rate is very slow and the material has dosimetric properties for the high dose radiation affected areas. The shape and structure of a glow peak were not changed after the fading study indicatee the absence of any other TL peak.

\subsection{Analysis of a trapping parameter}

The analysis of a trapping parameter is essential to evaluate the dosimetric properties of any TL peak. It can be performed in several ways such as Chen's peak shape method, initial rise method,

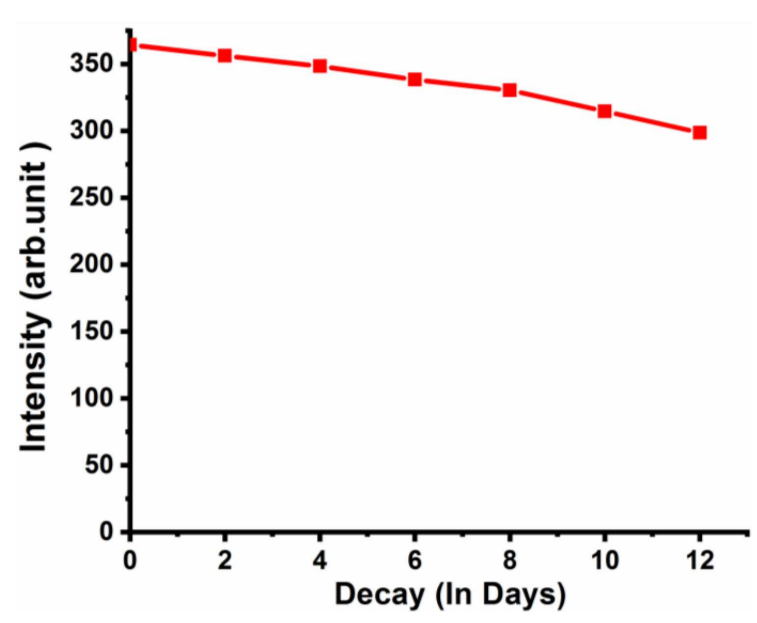

Fig. 7. TL fading characteristic of FLALC sample.

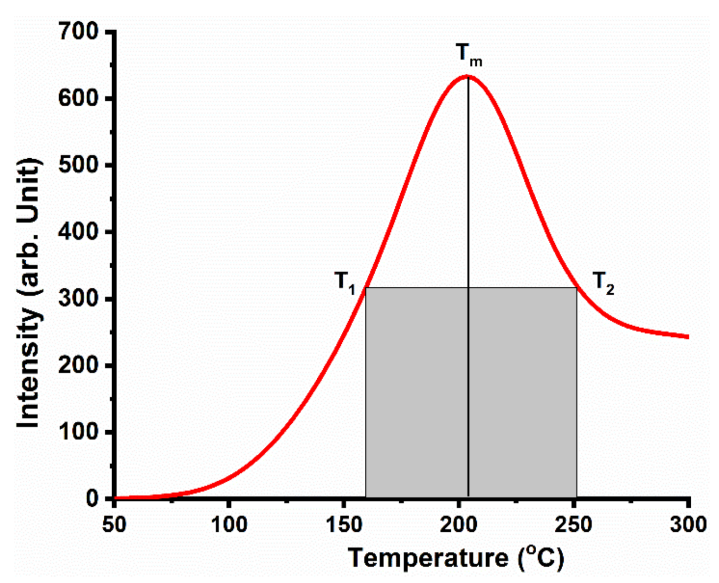

Fig. 8. TL glow curve of FLALC sample for 58.6 kGy $\gamma$-ray irradiation.

peak position method, isothermal decay method, curve fitting method, heating rate method, etc. depending on the nature and type of the TL glow curve. In the present work, we have only used Chen's peak shape method for analysis of trapping parameters due to simple and single glow curve nature of TL glow peak. Chen's peak shape method allows to calculate the activation energy of any TL glow peak:

$$
E_{\alpha}=C_{\alpha}\left(\frac{k_{\mathrm{B}} T_{m}^{2}}{\alpha}\right)-b_{\alpha}\left(2 k_{\mathrm{B}} T_{m}\right)
$$

In the above equation $\alpha$ can take three different values: $T, \delta$, and $\omega$. These three values produce three different equations to evaluate activation energies $E_{T}, E_{\delta}$, and $E_{\omega}$. The average of these three activation energies defines the final activation energy. Here, $\tau, \delta$, and $\omega$ are the shape parameters, and $b_{\alpha}$ and $C_{\alpha}$ are constants which depend on the different $\alpha$ values, and $T_{m}$ is the maximum temperature. Once the value of activation energy is determined, we can estimate the frequency factor using

$$
s=\frac{\beta E}{k_{\mathrm{B}} T_{m}^{2}} \exp \left(\frac{E}{k_{\mathrm{B}} T m}\right)\left(1-(b-1) \delta_{m}\right) .
$$


TABLE III

Trapping parameter of FLALC sample irradiated at 44.2 kGy dose.

\begin{tabular}{c|c|c}
\hline \hline $\begin{array}{c}\text { Geometrical } \\
\text { factor } \mu\end{array}$ & $\begin{array}{c}\text { Activation } \\
\text { energies }[\mathrm{eV}]\end{array}$ & $\begin{array}{c}\text { Frequency } \\
\text { factor }\left[\mathrm{s}^{-1}\right]\end{array}$ \\
\hline 0.532 & $E_{\tau}=0.9636$ & $7.63 \times 10^{7}$ \\
& $E_{\delta}=0.6624$ & \\
& $E_{\omega}=0.8127$ & \\
& $E_{\mathrm{avg}}=0.8127$ &
\end{tabular}

Here, $\beta$ is a linear heating rate when the TL glow curve was investigated, $\delta_{m}=\frac{2 k_{\mathrm{B}} T_{m}}{E}$. The value of order of kinetics can be obtained by calculating the value of a geometrical shape or symmetry factor of the TL glow peak. The geometrical shape or symmetry factor $\left(\mu_{g}\right)$ can be derived in such a way:

$$
\mu_{g}=\frac{\delta}{\omega}=\frac{T_{2}-T_{m}}{T_{2}-T_{1}}
$$

where $T_{m}$ is the maximum temperature of the TL glow peak and $T_{1}, T_{2}$ are the temperatures on either side of TM, corresponding to half intensity. Figure 8 represents the TL glow curve of FLALC sample for calculating the trapping parameters by Chen's peak shape method. The value of the geometrical factor as given in Table III shows the second-order kinetic behavior of the TL peak. Other trapping parameters are also tabulated in Table III $[20,21]$.

\subsection{Calculation of the total lifetime}

The calculation of the lifetime $(\tau)$ of a charge trap associated with any TL glow peak is vitally important for the dosimetric and dating characteristics. For illustration, electrons with $103 \leq \tau \leq 109$ years are expected to be useful in dating [22]. The lifetime of any glow peak gives information regarding the duration of time over which the trapped charges will completely vanish from their trapping center. In addition, recent research has proved that $\tau$ is of great importance in designing scintillators and persistent luminescence materials. With the help of trapping parameters as indicated above, the value of lifetime can be calculated using

$$
\tau=\frac{1}{s} \exp \left(\frac{E}{k_{\mathrm{B}} T}\right)
$$

where $\tau$ is the lifetime (s), $E$ is activation energy $(\mathrm{eV}), T$ is the storage temperature $(\mathrm{K})$, $k_{\mathrm{B}}$ is the Boltzmann constant $(\mathrm{eV} / \mathrm{K})$, and $s$ denotes the frequency factor. We have assumed that $T=300 \mathrm{~K}$. The calculated value of the lifetime of $203^{\circ} \mathrm{C}$ TL peak is $5.9382 \times 10^{9}$. Such a high value of the TL peak lifetime indicates stable properties of FLALC material and its suitability for dosimetric application.

\section{Conclusion}

Fly ash composite materials with a divalent anion are synthesized via simple solid-state synthesis reaction. The XRD pattern indicates the presence of quartz $\left(\mathrm{SiO}_{2}\right)$, mullite $\left(3 \mathrm{Al}_{2} \mathrm{O}_{3}-\mathrm{SiO}_{2}\right)$, and calcium oxide $(\mathrm{CaO})$ phases. The SEM micrograph shows spherical-shaped microparticles of fly ash composites. The TL glow curves of six different fly ash composite samples were studied after ${ }^{60} \mathrm{Co} \gamma$-rays exposure. FLALC sample has a well-defined and intense single TL peak at $199^{\circ} \mathrm{C}$. Hence, FLALC sample was exposed to different doses from $7.2 \mathrm{kGy}$ to $73 \mathrm{kGy}$. The linear response was observed up to the dose limit of $58.6 \mathrm{kGy}$. Increasing doses have not shown any changes in shape and position of the $199^{\circ} \mathrm{C}$ peak. According to Chen's peak shape method, the most intense glow peak of FLALC sample follows second-order kinetics. We also calculated the trapping parameters such as activation energy $(E)$ and frequency factor $(s)$ using Chen's peak shape method. Fading characteristics of FLALC sample were also recorded and a total loss of TL signal was $18 \%$ after twelve days of a storage period. The total lifetime of the TL glow peak was $5.9382 \times 10^{9}$ s. $\quad$ FLALC sample represents strong stability and potential for TL dosimetric application as compared to pure fly ash sample under normal environmental conditions.

\section{Acknowledgments}

Yatish R. Parauha is thankful to the Department of Science and Technology (DST), India, for financial support through INSPIRE fellowship (INSPIRE Code - IF180284).

\section{References}

[1] S. Dawn, P.K. Tiwari, A.K. Goswami, M.K. Mishra, Renew. Sust. Energ. Rev. 62, 215 (2016).

[2] O. Ellabban, H. Abu-Rub, F. Blaabjerg, Renew. Sust. Energ. Rev. 39, 748 (2014).

[3] P.A. Owusu, S.A. Sarkodie, Cogent Eng. 3, 1167990 (2016).

[4] M. Knapek, T. Hían, P. Dobron, F. Chmelik, A. Trnik, I. Stubna, Acta Phys. Pol. A 128(4), 783 (2015).

[5] R.K. Ileri, S. Haciyakupoglu, A.N. Esen, E. Oruçiglu, S. Erentürk, Acta Phys. Pol. A 127 (4), 1010 (2015).

[6] D. Ramachandran, R.P. George, V. Vishwakarma, U.K. Mudali, KSCE J. of Civil Eng. 21(4), 1282 (2017).

[7] I. Akkurt, K. Günoğlu, C. Başyiğit, A. Akkas,, Acta Phys. Pol. A 123 (2), 374 (2013).

[8] O. Bordun, B. Bordun, I. Medvid, I. Kukharskyy, Acta Phys. Pol. A 133 (4), 910 (2018).

[9] N. Salah, J. Phys. D. Appl. Phys. 41, 155302 (2008). 
[10] S. Joshi, K.K. Gupta, S.K. Ubale, S.J. Dhoble, Radiat. Meas. 105, 47 (2017).

[11] E. Salama, H.A. Soliman, Radiat. Phys. Chem. 148, 95 (2018).

[12] K.K. Gupta, N.S. Dhoble, D.K. Burghate, S.J. Dhoble, Lumin. 33, 947 (2018).

[13] S. Tamboli, R.M. Kadam, B. Rajeswari, B. Singh, S.J. Dhoble, J. Lumin. 203, 267 (2018).

[14] S. Mahajna, Y.S. Horowitz, J. Phys. D: Appl. Phys. 30, 2603 (1997).

[15] A.H. Oza, N.S. Dhoble, K. Park, S.J. Dhoble, Lumin. 30[6], 768 (2014).

[16] C. Malik, R. Meena, P. Rathi, B. Singh, A. Pandey, Radiat. Phys. Chem. 168, 108561 (2019).

[17] M.S. Bhadane, K.H. Gavhane, P.P. Kulkarni, S.S. Dahiwale, V.N. Bhoraskar, M.A. More, P.S. Patil, S.D. Dhole, J Lumin. 223, 117168 (2020).
[18] K.H. Gavhane, M.S. Bhadane, A.S. Bhoir, P.P. Kulkarni, B.J. Patil, V.N. Bhoraskar, S.D. Dhole, S.S. Dahiwale, J. Alloys Compd. 817, 152805 (2020).

[19] Y.A. Abdel-Razek, J. Taibah Univ. Sci. 10, 286 (2016).

[20] V. Pagonis, G. Kitis, C. Furetta, Numerical and Practical Exercises in Thermoluminescence, Springer, 2006.

[21] G. Kitis, J.M. Gomez-Ros, J.W.N. Tuyn, J. Phys. D. Appl. Phys. 31, 2536 (1998).

[22] N.D. Sang, N.V. Hung, T.V. Hung, N.Q. Hien, J. Taibah. Univ. Sci. 12[6], 846 (2018). 